\title{
Classification of the taxon 2 and taxon 3 complex of Bisgaard within Gallibacterium and description of Gallibacterium melopsittaci sp. nov., Gallibacterium trehalosifermentans sp. nov. and Gallibacterium salpingitidis sp. nov.
}

\author{
Magne Bisgaard, ${ }^{1}$ Bozèna M. Korczak, ${ }^{2}$ Hans-Jürgen Busse, ${ }^{3}$ \\ Peter Kuhnert, ${ }^{2}$ Anders Miki Bojesen ${ }^{1}$ and Henrik Christensen ${ }^{1}$ \\ ${ }^{1}$ Department of Veterinary Pathobiology, Faculty of Life Science, University of Copenhagen, 4 \\ Stigbøjlen, DK-1870 Frederiksberg C, Denmark \\ ${ }^{2}$ Institute of Veterinary Bacteriology, Vetsuisse Faculty of the University of Bern, Laenggass- \\ Strasse 122, CH-3001 Bern, Switzerland \\ ${ }^{3}$ Institut für Mikrobiologie und Genetik, Universität Wien, A-1030 Vienna, Austria
}

Correspondence

Henrik Christensen hech@life.ku.dk
This investigation was based on 23 isolates from several European countries collected over the past 30 years, and included characterization of all isolates. Published data on amplified fragment length polymorphism typing of isolates representing all biovars as well as protein profiles were used to select strains that were then further characterized by polyamine profiling and sequencing of $16 \mathrm{~S}$ rRNA, infB, rpoB and recN genes. Comparison of $16 \mathrm{~S}$ rRNA gene sequences revealed a monophyletic group within the avian 16S rRNA group of the Pasteurellaceae, which currently includes the genera Avibacterium, Gallibacterium and Volucribacter. Five monophyletic subgroups related to Gallibacterium anatis were recognized by $16 \mathrm{~S}$ rRNA, rpoB, infB and recN gene sequence comparisons. Whole-genome similarity between strains of the five subgroups and the type strain of $G$. anatis calculated from $r e c N$ sequences allowed us to classify them within the genus Gallibacterium. In addition, phenotypic data including biochemical traits, protein profiling and polyamine patterns clearly indicated that these taxa are related. Major phenotypic diversity was observed for $16 \mathrm{~S}$ rRNA gene sequence groups. Furthermore, comparison of whole-genome similarities, phenotypic data and published data on amplified fragment length polymorphism and protein profiling revealed that each of the five groups present unique properties that allow the proposal of three novel species of Gallibacterium, for which we propose the names Gallibacterium melopsittaci sp. nov. (type strain $\mathrm{F} 450^{\top}=\mathrm{CCUG} 36331^{\top}=\mathrm{CCM} 7538^{\top}$ ), Gallibacterium trehalosifermentans sp. nov. (type strain $52 / \mathrm{S} 3 / 90^{\top}=\mathrm{CCUG} 55631^{\top}=\mathrm{CCM}$ $7539^{\top}$ ) and Gallibacterium salpingitidis sp. nov. (type strain $\mathrm{F} 150^{\top}=\mathrm{CCUG} 15564^{\top}=\mathrm{CCUG}$ $36325^{\top}=$ NCTC $11414^{\top}$ ), a novel genomospecies 3 of Gallibacterium and an unnamed taxon (group V). An emended description of the genus Gallibacterium is also presented.
Organisms associated with salpingitis and peritonitis in ducks were first reported as atypical Actinobacillus

Abbreviation: AFLP, amplified fragment length polymorphism.

The GenBank/EMBL/DDBJ accession numbers for the $16 \mathrm{~S}$ rRNA, infB, $r p o B$ and recN gene sequences determined in this study are detailed in Supplementary Table S1.

Details of strains and sequence accession numbers, whole-genome similarity values and a comparison with DNA-DNA reassociation results and phylogenetic trees based on infB, rpoB and recN gene sequences are available as supplementary material with the online version of this paper. lignieresii by Bisgaard (1975). Comparative investigations of avian-associated members of the Pasteurellaceae including additional isolates of atypical Actinobacillus lignieresii obtained from ducks, geese and pigeons subsequently resulted in classification of these organisms as taxa 2 and 3 based upon differences in production of acid from $(+)$-Larabinose and dulcitol (Bisgaard, 1982).

A total of 35 strains isolated from the respiratory tract, liver, heart and spleen of pigeons and different species of the Psittaciformes were reported by Beichel (1986). Nineteen of these were reinvestigated by Bisgaard et al. 
(1999) and biotyped as described previously (Bisgaard, 1993). Considering these examinations, the host spectrum of these organisms was extended to include galliform birds like partridges and pheasants (Bisgaard, 1993). The importance of taxa 2 and 3 in salpingitis in web-footed birds was subsequently confirmed by Bisgaard (1995). On the basis of DNA-DNA hybridizations, these taxa were shown to form a large, distinct group which seems to represent a new genus with several species within the family Pasteurellaceae Pohl 1981 (Piechulla et al., 1985). However, full-matrix DNADNA hybridizations were not carried out.

De Ley et al. (1990) performed hybridizations between labelled rRNA from seven representative members of the family Pasteurellaceae and 53 strains of the Pasteurellaceae and showed that strain HIM 730-3 (=F420) of taxon 2/3 (according to Bisgaard et al., 1993 and not taxon 2 as listed by De Ley et al., 1990) and strain NCTC 11412 of taxon 3 biovar 2 clustered with different nodes of the rRNA branches outlined, indicating major genetic diversity within taxa 2 and 3.

Different polyamine patterns were obtained with a duck isolate of taxon 2 biovar $1\left(\mathrm{~F} 150^{\mathrm{T}}\right)$ and a parakeet isolate of taxon 3 biovar $1\left(\mathrm{~F}_{5} 0^{\mathrm{T}}\right)$ according to Busse et al. (1997). Both isolates had profiles different from those of the newly established genera Gallibacterium (Christensen et al., 2003a) and Avibacterium (Blackall et al., 2005) of avian origin. Comparison of phena defined by protein profiling with species/groups previously established by DNA-DNA hybridization, carbohydrate profiling and biovar typing showed that the best correlation existed between DNADNA hybridization and biovar typing (Bisgaard et al., 1993). A correlation between results obtained from DNADNA hybridizations and protein profiling was not observed. Protein profiling, however, indicated a connection between protein profiles and hosts of isolation (Bisgaard et al., 1993). Host-related bacterial lineages of the taxon 2 and 3 complex have subsequently been demonstrated by amplified fragment length polymorphism (AFLP) typing (Bojesen et al., 2007).

Phylogenetic analysis by 16S rRNA gene sequence comparison has shown that taxon 2 biovar 1 (represented by NCTC $11414^{\mathrm{T}}$ ) and taxon 3 biovar 2 (represented by CCUG $15565^{\mathrm{T}}$, wrongly referred to as CCUG 15563 by Dewhirst et al., 1993) cluster together, forming subcluster 3D of Dewhirst, together with strains later classified as Gallibacterium and [Pasteurella] langaaensis (Dewhirst et al., 1993). In a subsequent investigation including avian taxa, Bisgaard taxon 2 and taxon 3 formed a separate entity within the so-called avian cluster (Christensen et al., 2003b). A single isolate from septicaemia in a budgerigar classified as trehalose-positive taxon 3 biovar 1 showed only $94.5 \% 16$ S rRNA gene sequence similarity to biovar 2 of taxon 3, underlining the heterogeneity of this complex group (Christensen et al., 2003b).

The accumulated evidence outlined above underlines the present uncertain taxonomic situation of the taxon 2 and taxon 3 complex of avian origin and the lack of unambiguous diagnostic tests associated with these organisms, which makes interpretation of studies difficult and prevents progress in understanding their epidemiology and pathogenesis. For the same reasons, the aims of the present investigation were to clarify the taxonomic position(s) of the taxon 2 and 3 complex.

In the present study, a subset of 23 strains representing existing biovars characterized by AFLP profiling (Bojesen et al., 2007) were investigated by phylogenetic analysis of the $16 \mathrm{~S}$ rRNA, rpoB, infB and recN gene sequences. Moreover, $\operatorname{recN}$ gene sequences were used for estimation of whole-genome similarity to allow comparison with previously published DNA-DNA hybridizations. Selected strains were additionally characterized by polyamine profiling. Clusters outlined by Bojesen et al. (2007) and shown not to belong to Gallibacterium sensu stricto were excluded from the present paper, and these taxa will be described separately.

\section{Bacterial strains}

A total of 23 strains representing AFLP clusters 1, 4, 6 and 7 identified by Bojesen et al. (2007) were investigated (Table 1). Compared with the study of Bojesen et al. (2007), isolate $5436 / \mathrm{S} 6 / 89$ in the current study appeared as $5436 / \mathrm{S6} / 88$, and $52 / \mathrm{S} 3 / 90$ in the current study appeared as 52/90. These strains were listed incorrectly by Bojesen et al. (2007).

\section{Sequencing of 165 rRNA, rpoB, infB and recN genes}

$16 \mathrm{~S}$ rRNA gene sequencing of 13 strains was performed as reported previously (Angen et al., 2003; Christensen et al., 2002) in Copenhagen yielding at least $1296 \mathrm{bp}$ of the $16 \mathrm{~S}$ rRNA gene sequence. In addition, 18 strains were sequenced in Bern as previously reported by Kuhnert et al. (2002), generating $1360 \mathrm{bp}$ of the 16S rRNA gene sequence. Eight strains were sequenced independently in both laboratories to allow for comparison of variation (Supplementary Table S1, available in IJSEM Online). One of these was reported in a previous study (Christensen et al., 2003b). Duplicated 16S rRNA gene sequences from eight strains (Supplementary Table S1) showed between 100 and $99.6 \%$ similarity $\left(\mathrm{F} 150^{\mathrm{T}}\right.$ and $\left.\mathrm{F} 151\right)$, resulting from ambiguous positions due to multiple rRNA operons.

Sequencing of $r p o B$ and infB genes was performed according to protocols described previously (Korczak et al., 2004; Kuhnert et al., 2004). In addition, recN gene sequences were used as a representative target for determining whole-genome similarity as described by Kuhnert \& Korczak (2006), including 1400 bp of the gene. Whole genome similarity values were calculated based on the formula $S I_{\text {genome }}=-1.30+2.25 S I_{\text {recN }}$ of Zeigler (2003), where $S I_{\text {genome }}$ is the predicted DNA sequence identity shared by the genomes and $S I_{r e c N}$ is the sequence similarity between $r e c N$ orthologues. 
Table 1. Strains of Bisgaard taxa 2 and 3 subjected to $16 \mathrm{~S} r R N A$, infB, $r p o B$ and $r e c N$ gene sequencing and classified within Gallibacterium

\begin{tabular}{|c|c|c|c|c|c|c|}
\hline Strain & 16S rRNA group & Taxon & Biovar & AFLP cluster & Host & Lesion \\
\hline \multicolumn{7}{|l|}{ Gallibacterium melopsittaci sp. nov. } \\
\hline 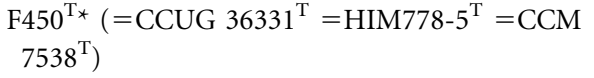 & I & 3 & 1 & 6 & Parakeet & Septicaemia \\
\hline F417 (=HIM698-6) & I & $2 / 3$ & 5 & 6 & Parakeet & Septicaemia \\
\hline $3077 / 89$ & I & $2 / 3$ & 5 & 6 & Budgerigar & Septicaemia \\
\hline $1596 / S 4 / 90$ & I & 3 & 9 & 6 & Budgerigar & Septicaemia \\
\hline F292 (=CCUG 36332) & I & 3 & 1 & 6 & Parakeet & Salpingitis \\
\hline $5436 / S 6 / 89$ & I & 3 & 1 & 6 & Budgerigar & Septicaemia \\
\hline F420* (=HIM730-3) & I & $2 / 3$ & 1 & 6 & Parakeet & Septicaemia \\
\hline F416 $6^{*}(=$ HIM778-3 & I & 2 & 4 & 6 & Parakeet & Septicaemia \\
\hline \multicolumn{7}{|l|}{ Gallibacterium trehalosifermentans sp. nov. } \\
\hline $52 / \mathrm{S} 3 / 90^{\mathrm{T}}\left(=\right.$ CCUG $\left.55631^{\mathrm{T}}=\mathrm{CCM} 7539^{\mathrm{T}}\right)$ & II & $2 / 3$ & $5 \mathrm{Tre}^{+}$ & 6 & Budgerigar & Septicaemia \\
\hline F448* $(=$ CCUG 36333) & III & 3 & 2 & 1 & Parakeet & Rhinitis \\
\hline F298 & III & 3 & 4 & 1 & Duck & Septicaemia \\
\hline $19060 / 1120^{*}$ & III & 3 & 6 & 1 & Pigeon & Pneumonia \\
\hline $59 / \mathrm{S} 3 / 89^{*}$ & III & 3 & 7 & 1 & Turkey & Septicaemia \\
\hline $282 / \mathrm{S} 4 / 90^{*}$ & III & $2 / 3$ & 2 & 1 & Budgerigar & Septicaemia \\
\hline \multicolumn{7}{|l|}{ Gallibacterium salpingitidis sp. nov. } \\
\hline $\begin{array}{l}\mathrm{F} 150^{\mathrm{T}}\left(=\text { CCUG } 15564^{\mathrm{T}}=\text { CCUG } 36325^{\mathrm{T}}\right. \\
\left.=\text { NCTC } 11414^{\mathrm{T}}\right)\end{array}$ & IV & 2 & 1 & 4 & Duck & Salpingitis \\
\hline $18469 / 18^{\star}$ & IV & 2 & 3 & 4 & Duck & Salpingitis \\
\hline BK1010/1 & IV & 3 & 5 & 4 & Cow & Pericarditis \\
\hline $19987 / 2$ & IV & 2 & 4 & 4 & Goose & Salpingitis and peritonitis \\
\hline
\end{tabular}

*Total protein profiles characterized by Bisgaard et al. (1993).

Searches for sequences in public databases were performed by BLAST (Altschul et al., 1997). Multiple alignments were constructed by CLUSTAL_X (Thompson et al., 1997). Phylogenetic analysis of the $16 \mathrm{~S}$ rRNA, infB, rpoB and $r e c N$ gene sequences was carried out by neighbour joining using Jukes-Cantor correction in Bionumerics v. 4.5 (Applied Maths). Both individual and combined trees were constructed.

$16 \mathrm{~S}$ rRNA, rpoB, infB and $r e c N$ gene sequence-based phylogenetic analysis of strains previously classified with the taxon 2 and 3 complex of Bisgaard was performed with all strains sequenced in the present study as well as published sequences of all members of Gallibacterium and related strains. The results documented that the strains investigated formed a monophyletic group within the Pasteurellaceae, closely related to Gallibacterium and unrelated to other genera including Avibacterium (Fig. 1 and Supplementary Fig. S1). To provide a simplified overview of the phylogenetic results, only strains included in the cluster following analysis of each of the 16S rRNA, $r p o B$, inf $B$ and $r e c N$ gene sequences are shown on Fig. 1 and Supplementary Fig. S1. More detailed phylogenetic comparisons performed by maximum-likelihood analysis including bootstrap analysis were also performed by fastDNAml (Felsenstein, 1995; Olsen et al., 1994) and supported conclusions drawn from the above-mentioned neighbour-joining analysis (data not shown).

Nine strains $\left(\mathrm{F} 420, \mathrm{~F} 292, \mathrm{~F} 450^{\mathrm{T}}, \mathrm{HPA} 129, \mathrm{~F} 416, \mathrm{~F} 417\right.$, 5436/S6/89, 1596/S4/90 and 3077/89) clustered together (group I) in the 16S rRNA gene sequence-derived tree, showing similarities between $99.5 \%\left(\mathrm{~F} 420\right.$ to $\mathrm{F} 450^{\mathrm{T}}$ ) and $100 \%$ (Fig. 1). These strains also clustered together in the $r p o B$, infB and $r e c N$ sequence-derived trees (Supplementary Fig. S1).

Two strains (52/S3/90 ${ }^{\mathrm{T}}$ and B7/99/1) showed $16 \mathrm{~S}$ rRNA gene sequence similarities of $98.3 \%$ and formed a second cluster (group II). These strains also grouped together in the $r p o B$, infB and recN trees (except for B7/99/1; recN not sequenced) (data not shown). Phylogenies shown in Fig. 1 


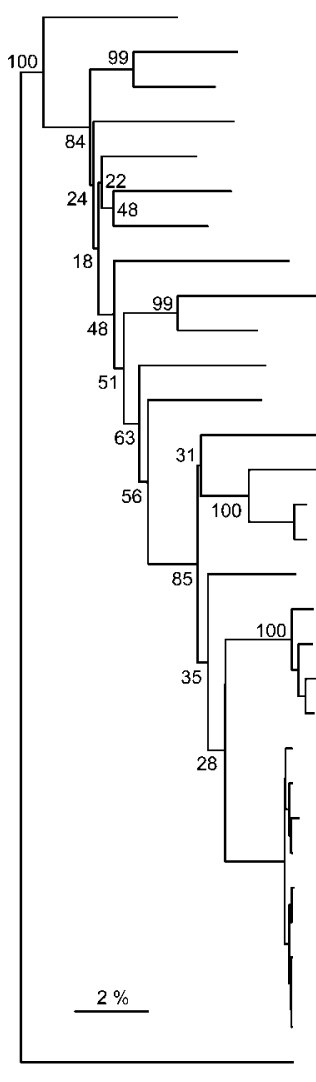

\begin{tabular}{|c|c|c|}
\hline Phocoenobacter uteri & NCTC $12872^{\top}$ & $\times 89379$ \\
\hline Mannheimia haemolytica & NCTC $9380^{\top}$ & M75080 \\
\hline Actinobacillus lignieresii & NCTC $4189^{\top}$ & AY362892 \\
\hline Lonepinella koalarum & ATCC $700131^{\top}$ & Y17189 \\
\hline Bibersteinia trehalosi & NCTC $10370^{\top}$ & AY362927 \\
\hline Nicoletella semolina & CCUG $43639^{\top}$ & AY508816 \\
\hline Pasteurella multocida subsp. multocida & CCUG $17976^{\top}$ & $\mathrm{AF} 294410$ \\
\hline Histophilus somni & HS8025' & AF549387 \\
\hline Aggregatibacter actinomycetemcomitans & HK1651 & * \\
\hline Haemophilus influenzae & $\mathrm{Rd}$ KW20 & NC_000907 \\
\hline Avibacterium gallinarum & NCTC $11188^{\top}$ & AY362921 \\
\hline Volucribacter psittacicida & CCUG $47536^{\top}$ & AY216868 \\
\hline Gallibacterium anatis & CCUG $15563^{\top}$ & AF228001 \\
\hline Galibacterium group $\mathrm{V}$ & $39199 / 1 \mathrm{~L}$ & EU424002 \\
\hline Gallibacterium salpingitidis IV & $19987 / 2$ & EU424001 \\
\hline Gallibacterium salpingitidis IV & $\mathrm{F} 150^{\top}$ & EU424000 \\
\hline Gallibacterium trehalosifermentans II & $52 / S 3 / 90^{\top}$ & EU423994 \\
\hline Galibacterium genomospecies 3 III & $59 / S 3 / 89$ & EU423999 \\
\hline Gallibacterium genomospecies 3 III & $3565 / \mathrm{S} 2 / 89$ & EU423997 \\
\hline Gallibacterium genomospecies 3 III & F151 & EU423996 \\
\hline Gallibacterium genomospecies 3 III & F448 & EU423998 \\
\hline Galibacterium melopsittaci I & F416 & EU423992 \\
\hline Gallibacterium melopsittacil & $\mathrm{F} 420$ & EU423991 \\
\hline Gallibacterium melopsittacil & $\mathrm{F} 450^{\top}$ & EU423985 \\
\hline Gallibacterium melopsittacil & $\mathrm{F} 292$ & EU423990 \\
\hline Gallibacterium melopsittaci I & $3077 / 89$ & EU423987 \\
\hline Gallibacterium melopsittacil & $\mathrm{F} 417$ & EU423986 \\
\hline Gallibacterium melopsittacil & $5436 / \$ 6 / 89$ & EU423993 \\
\hline Gallibacterium melopsittacil & $1596 / S 4 / 90$ & EU423988 \\
\hline Gallibacterium melopsittacil & HPA129 & EU423989 \\
\hline Escherichia coli & K-12 MG1655 & NC_000913 \\
\hline
\end{tabular}

Fig. 1. Phylogenetic relationships between strains of Gallibacterium and type species of genera of the Pasteurellaceae based on 16S rRNA gene sequences. Jukes-Cantor correction was applied for the distance matrix and the neighbour-joining method was used for tree construction in Bionumerics. Bootstrap values from 500 experiments are given as percentages at branches. Bar, $2 \%$ sequence divergence. *, Sequence available at http://www. genome.ou.edu. and Supplementary Fig. S1 are based on strains analysed by sequencing all four genes, which explains why group II contains only one strain. Groups I and II were closely related, and demonstrated 16S rRNA gene sequence similarities between $96.2 \%$ (F420 and B7/99/1) and 96.9\% (F416 and B7/99/1).

Four strains (F151, 3565/S2/89, F448, 59/S3/89) formed a third group (group III) in the 16S rRNA gene sequencederived tree, showing a maximum of $99.3 \%$ similarity, as observed between strain F448 and 3565/S2/89. Bootstrap support of $100 \%$ was found for group III (Fig. 1). Group III was also recognized by phylogenetic analysis of housekeeping genes (Supplementary Fig. S1).

According to $16 \mathrm{~S}$ rRNA gene sequence-based analysis, the four strains $\mathrm{F} 150^{\mathrm{T}}$, BK1010/1, 18469/18 and 19987/2 formed group IV, with at least $99.2 \%$ similarity $\left(\mathrm{F} 150^{\mathrm{T}}\right.$ and 18469 / 18) (only two strains are shown in Fig. 1). The group was linked to strain 39199/1L (group V) by 16S rRNA gene sequence similarities between $96.4 \%(18469 / 18)$ and $96.6 \%$ (BK1010/1). Groups IV and V were supported by a bootstrap value of $100 \%$. Groups IV and V were also recognized as separate groups by phylogenetic analysis of housekeeping gene sequences (Supplementary Fig. S1).

In $16 \mathrm{~S}$ rRNA as well as housekeeping gene-based phylogenetic analyses, $16 \mathrm{~S}$ rRNA groups I-V and Gallibacterium always formed a monophyletic unit (Fig. 1 and Supplementary Fig. S1). The lowest similarity of $16 \mathrm{~S}$
rRNA gene sequences for these taxa was $91.9 \%$ (3191/88 of Gallibacterium genomospecies 1 with $18469 / 18$ of group IV). Most genera of the Pasteurellaceae are related at below approximately $95 \%$ 16S rRNA gene sequence similarity. Establishing a new genus based only upon 16S rRNA groups $\mathrm{I}-\mathrm{V}$ increases the overall minimum similarity to $93.2 \%\left(\mathrm{~F} 450^{\mathrm{T}}\right.$ of group I - 39199/lL of group V). However, phenotypic separation of this group from Gallibacterium seems impossible (see Table 3).

There was a trend towards Gallibacterium anatis forming an outgroup to groups I-V (Fig. 1 and Supplementary Fig. S1). Phylogenetic analysis of translated housekeeping gene sequences confirmed the analysis performed at the $16 \mathrm{~S}$ rRNA gene sequence level, although $16 \mathrm{~S}$ rRNA groups I-V could not always be separated (data not shown).

Whole-genome similarity values calculated from recN sequences of strains investigated and type species of the genera Gallibacterium, Volucribacter and Avibacterium appear in Supplementary Table S2. All strains representing $16 \mathrm{~S}$ rRNA gene sequence clusters I-V showed similarity values of $0.42,0.40,0.36-0.37,0.38-0.39$ and 0.36 , respectively, with the type strain of the type species $G$. anatis. Whole-genome similarity values calculated from $r e c N$, however, showed values of just $0.00-0.06$ with the type species of Avibacterium and Volucribacter.

Whole-genome similarity values calculated from $\mathrm{recN}$ sequences confirmed the existence of phylogenetic groups 
outlined by comparison of housekeeping and 16S rRNA gene sequences (Supplementary Table S2). Whole-genomederived similarity values based on recN ranging between 0.93 and 0.95 were observed for the nine strains making up group I, while values observed between group I and groups II-V ranged between 0.42 and 0.62 , suggesting classification within the same genus. Similarity values observed between group II and the other four groups ranged between 0.42 and 0.62 . Strains representing group III showed whole-genome similarities ranging between 0.89 and 0.93 , while values with groups I-II and IV-V varied between 0.39 and 0.52 . A whole-genome similarity of 0.87 was observed for the two strains representing group IV, similarity values with the other groups ranging between 0.45 and 0.50 . Finally, the single strain representing group $\mathrm{V}$ showed similarity values with groups I-IV ranging from 0.39 to 0.49 . In summary, G. anatis and all five groups are linked by whole-genome similarity values above 0.40 (Supplementary Table S2).

\section{Phenotypic characteristics}

Due to major within-group variations, genotypic groupings as stated above were not confirmed by the polyamine patterns (Table 2). Similar variations were observed for established species like G. anatis (Table 2). Mean percentages of the total amount of polyamines calculated for the single polyamines, however, seem to indicate that 1,3-diaminopropane is the dominant polyamine in some strains of group III and the strain of group V. The predominant compound spermidine and large amounts of putrescine were common to the two representatives of group I. Large amounts of either 1,3-diaminopropane or cadaverine were also detected. The single representative of group IV exhibited the major compounds putrescine and spermidine. Like the type strain of G. anatis and two other strains of this species, strains of group III and V showed a polyamine pattern with three predominant compounds, 1,3-diaminopropane, putrescine and spermidine. However, the content of putrescine can be quite small, as found in strain CCM 5974 of Gallibacterium genomospecies 1.

All strains investigated were Gram-negative, non-motile at 22 and $37^{\circ} \mathrm{C}$ and fermentative in Hugh \& Leifson's medium with glucose. Negative reactions were obtained in growth on Simmons' citrate, growth with $\mathrm{KCN}$ and the Voges-Proskauer reaction at $37{ }^{\circ} \mathrm{C}$ and $\mathrm{H}_{2} \mathrm{~S}$ was not produced in triple-sugar iron (TSI) medium. Gas was not produced from nitrate and none of the strains produced arginine dihydrolase, lysine decarboxylase, ornithine decarboxylase, phenylalanine deaminase, gelatinase or pigment. Symbiotic growth and haemolysis of bovine blood were not observed and the isolates did not hydrolyse Tween 20 or 80 . All isolates were positive for the porphyrin, methyl red and phosphatase tests, reduced nitrate and produced alanine aminopeptidase. None of the isolates investigated produced acid from meso-erythritol, adonitol, $(-)$-L-xylose, (+ )-D-fucose, (+)-L-rhamnose, (-)-L-sorbose, maltose, cellobiose, $(+)$-melezitose, $(+)$-glycogen,

Table 2. Polyamine patterns of strains investigated

Values are given as $\mu \mathrm{mol}(\mathrm{g} \text { dry weight })^{-1}$, with percentages of the total given in parentheses. $\operatorname{tr}$, Trace [less than $0.05 \mu \mathrm{mol}(\mathrm{g} \text { dry weight })^{-1}$ ]; - , not detected. Abbreviations: DAP, 1,3-diaminopropane; PUT, putrescine; CAD, cadaverine; SPD, spermidine; HSPD, sym-homospermidine; SPM, spermine. None of the strains contained tyramine or sym-norspermidine.

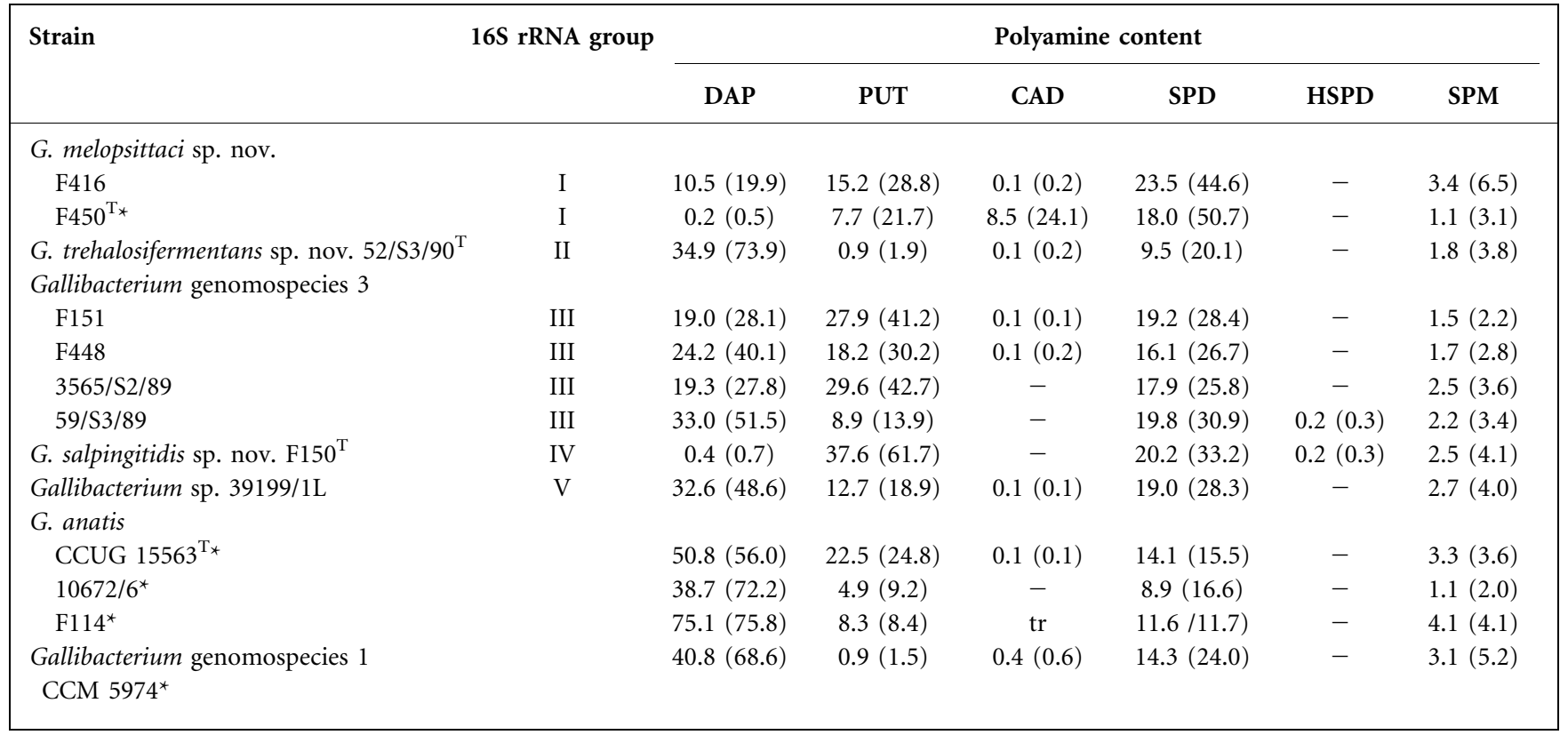

${ }^{\star}$ Data from Busse et al. (1997). 
Table 3. Phenotypic characters that separate the strains investigated

Taxa: 1, G. melopsittaci sp. nov.; 2, G. trehalosifermentans sp. nov.; 3, G. salpingitidis sp. nov.; 4, Gallibacterium genomospecies 3; 5, Gallibacterium group V; 6, G. anatis (data from Christensen et al., 2003a). Characters are scored as: + , all strains positive within 1-2 days; (+), all strains positive within 3-14 days; -, all strains negative after 14 days; w, weakly positive; $d$, some strains positive while others are negative (number of strains positive/number of strains tested).

\begin{tabular}{|c|c|c|c|c|c|c|}
\hline Character & 1 & 2 & 3 & 4 & 5 & 6 \\
\hline Catalase & d $5 / 9$ & d $1 / 2$ & + & $\mathrm{d} 6 / 7$ & + & + \\
\hline Oxidase, TMPD & d $3 / 9$ & $\mathrm{~d} 1 / 2$ & + & $\mathrm{d} 4 / 7$ & + & + \\
\hline Urease & - & - & d $2 / 4$ & $\mathrm{~d} 3 / 7$ & + & - \\
\hline Indole & - & - & - & d $1 / 7$ & - & - \\
\hline Growth on MacConkey agar & d $5 / 9$ & - & + & d $2 / 7$ & + & $\mathrm{d}$ \\
\hline \multicolumn{7}{|l|}{ Acid production from: } \\
\hline Mucate & $\mathrm{d} 4 / 9$ & - & + & $\mathrm{d} 2 / 7$ & + & - \\
\hline Glycerol & $(+)$ & $\mathrm{d} 1 / 2$ & $(+)$ & $\mathrm{d} 6 / 7$ & $(+)$ & + \\
\hline$(+)$-D-Arabitol & - & - & + & d $3 / 6$ & + & - \\
\hline Xylitol & - & - & $\mathrm{W}$ & - & - & - \\
\hline$(+)$-L-Arabinose & d $2 / 9$ & - & + & d $2 / 7$ & - & - \\
\hline$(-)$-D-Arabinose & $\mathrm{d} 1 / 9$ & $\mathrm{~d} 1 / 2$ & $(+)$ & d $2 / 6$ & $(+)$ & $\mathrm{d}$ \\
\hline$(-)$-D-Ribose & $+/(+)$ & $+/(+)$ & + & d $5 / 6$ & + & + \\
\hline$(+)$-D-Xylose & $\mathrm{d} 8 / 9$ & + & + & $+/(+)$ & - & + \\
\hline Dulcitol & d $3 / 9$ & $\mathrm{~d} 1 / 2$ & + & $\mathrm{d} 1 / 7$ & - & - \\
\hline (-)-D-Sorbitol & d $8 / 9$ & + & d $1 / 4$ & d $5 / 7$ & + & $\mathrm{d}$ \\
\hline$(-)$-L-Fucose & d $1 / 9$ & $+/(+)$ & + & d $3 / 6$ & + & $\mathrm{d}$ \\
\hline Lactose & $+/(+)$ & - & $(+)$ & $\mathrm{d} 6 / 7$ & + & $\mathrm{d}$ \\
\hline ONPG & + & - & + & + & + & + \\
\hline$(+)$-Melibiose & $+/(+)$ & $+/(+)$ & d $1 / 2$ & - & + & - \\
\hline Trehalose & - & + & - & - & - & $\mathrm{d}$ \\
\hline Raffinose & + & + & $+/(+)$ & $\mathrm{d} 6 / 7$ & + & + \\
\hline Dextrin & - & - & - & - & - & $\mathrm{d}$ \\
\hline \multicolumn{7}{|l|}{ Activity of: } \\
\hline$\alpha$-Galactosidase & + & + & $\mathrm{d} 1 / 2$ & - & + & - \\
\hline$\alpha$-Glucosidase (PNPG) & - & + & - & - & - & + \\
\hline$\beta$-Xylosidase (ONPX) & $+7 / 7$ & $\mathrm{~d} 1 / 2$ & + & d $2 / 6$ & - & - \\
\hline
\end{tabular}

inulin, aesculin, amygdalin, arbutin, gentiobiose, salicin, $(+)$-turanose or $\beta-N-\mathrm{CH}_{3}$-glucosamid. Negative reactions were also observed for $\beta$-glucosidase (NPG), $\alpha$-fucosidase (ONPF), $\beta$-glucuronidase (PGUA) and $\alpha$-mannosidase. Likewise, none of the strains produced gas from $(+)-\mathrm{D}-$ glucose. All strains produced acid from myo-inositol, (-)D-mannitol, ( - )-D-fructose, (+)-D-galactose, (+ )-D-glucose, $(+)$-D-mannose and sucrose. Variable reactions were observed for the remaining tests investigated (Table 3).

According to Table 3, one to nine phenotypic characters separate clusters $\mathrm{I}-\mathrm{V}$ defined according to genotypic characters as stated above. Major phenotypic diversity was observed for 16S rRNA gene sequence groups I and III, for which 10 and 17 characters showed different reactions, respectively, complicating phenotypic separation of the genotypic groups.

\section{Reassessment of Gallibacterium and outline of novel species}

A subset of 60 isolates of the taxon 2 and 3 complex of Bisgaard representing all biovars of the taxon 2 and 3 complex (53 isolates) and seven related isolates demonstrating atypical phenotypes were characterized previously by AFLP typing (Bojesen et al., 2007). Seven major AFLP clusters were identified using maximum-parsimony and bootstrap analyses. In the present study, seven, four, 11 and a single strain representing AFLP clusters 1, 4, 6 and 7, respectively, of Bojesen et al. (2007) were characterized by sequencing of $16 \mathrm{~S}$ rRNA, $r p o B$, infB and $\operatorname{rec} N$ genes and by analysis of polyamines. Phylograms observed with neighbour-joining and maximum-likelihood analyses of the four genes investigated confirmed the existence of clusters identified by AFLP except for AFLP cluster 6. Two strains, $52 / S 3 / 90$ and B7/99/1, branching deeply with the other strains of AFLP cluster 6, made up a separate group in phylogenies based upon 16S rRNA gene sequence and housekeeping genes.

16S rRNA gene sequence similarities within and between groups I-V clearly indicate the existence of novel species which should be classified within the same genus. 16S rRNA gene sequence groups I-V formed a separate cluster with the $G$. anatis complex and $16 \mathrm{~S}$ rRNA gene sequence similarities of 93.2-94.8\% were observed with the type 
strain of G. anatis. These observations confirm previous investigations on inter- and intrafamilial similarities of rRNA cistrons of the Pasteurellaceae by De Ley et al. (1990), who demonstrated that strain F151 (16S rRNA gene sequence group III) and strain CCM 5974 of Gallibacterium genomospecies 1 and strain 3348/80 of $G$. anatis were rooted at the base of the seven rRNA branches reported, while strain F420 (16S rRNA gene sequence group I) and $G$. anatis strain F114 were rooted at the common root of five rRNA branches.

Whole-genome similarity values calculated from $\mathrm{recN}$ sequences within the family Pasteurellaceae have previously indicated similarity values of approximately 0.40 and above for species classified within the same genus (Kuhnert \& Korczak, 2006; Kuhnert et al., 2007). G. anatis and all strains investigated representing $16 \mathrm{~S}$ rRNA gene sequence clusters I-V are linked by similarity values above 0.40 and should be classified within the same genus. In addition, phenotypic data including biochemical traits (Christensen et al., 2003a), protein profiling (Bisgaard et al., 1993) and polyamine patterns (Table 2) clearly indicate that these taxa are related.

DNA-DNA hybridizations between strains classified with $16 \mathrm{~S}$ rRNA gene sequence group I have previously included strains F450 $0^{\mathrm{T}}, \mathrm{F} 420, \mathrm{~F} 417$ and F416 (Piechulla et al., 1985). Strains $\mathrm{F} 417$ and $\mathrm{F} 450^{\mathrm{T}}$ showed $91 \%$ reassociation, while repetition showed only $51 \%$ DNA reassociation, underlining the uncertainty of the method. Only $71 \%$ DNA reassociation was observed between strains F417 and F420 belonging to group I in the current investigation, while strains F420 and F416 of the same group showed $75 \%$ DNA reassociation (Supplementary Table S3).

Assuming strain F283 might replace $\mathrm{F} 150^{\mathrm{T}}$ (group II), since $100 \%$ DNA reassociation was observed between these strains (Piechulla et al., 1985), and the observed $95 \%$ DNA reassociation between F416 (group I) and 19987/2 (group IV) is incorrect, DNA reassociation between 16S rRNA gene sequence group I (F416, F420) and groups III (F151, F448) and IV $\left(\mathrm{F} 150^{\mathrm{T}}, 19987 / 2\right)$ varied between $74 \%(\mathrm{~F} 283-$ F416) and 20\% (F420-F448), which is below the values normally observed for strains belonging to the same species of the Pasteurellaceae.

Kuhnert \& Korczak (2006) proposed that sequence comparison of the three genes $r e c N, r p o A$ and thdF could replace DNA-DNA hybridizations. They showed that even sequencing of a single gene, $r e c N$, might serve this purpose. With two recently described species of the Pasteurellaceae (Actinobacillus capsulatus and Avibacterium endocarditis), a correlation between DNA-DNA hybridization results and $r e c N$ similarity was demonstrated (Bisgaard et al., 2007; Kuhnert et al., 2007), and full matrices of recN similarity have extended the comparison based on the more limited DNA reassociation data. In the current investigation, the same approach has been followed, in that published DNA reassociation data have been complemented by full-matrix comparison of recN sequence similarity data.
DNA reassociation observed for group I (65-75\%; Supplementary Table S3) is slightly lower than the normal range of $80-85 \%$ for species of the family (Christensen $e t$ al., 2007). For $16 S$ rRNA gene sequence group I, both AFLP results (Bojesen et al., 2007) and whole-genome similarity values calculated from $\mathrm{recN}$ sequences of strains investigated (Supplementary Tables S2 and S3) clearly support the establishment of a novel species, for which the name Gallibacterium melopsittaci sp. nov. is proposed. Although phenotypically diverse (Tables 1 and 3), this species can be separated from both G. anatis (Christensen et al., 2003a) and the other 16S rRNA gene sequence groups outlined here (Table 3). Finally, this group also represents a welldefined group (phenon 1) according to protein profiling, as demonstrated previously by Bisgaard et al. (1993).

Gallibacterium 16S rRNA gene sequence group II represents a unique group of bacteria which can be separated from both previously reported taxa and the other groups investigated. Both $16 \mathrm{~S}$ rRNA gene sequence comparisons (Fig. 1) and whole-genome similarity values calculated from recN sequences (Supplementary Table S2) show clearly that this group should be classified as a novel species of Gallibacterium, Gallibacterium trehalosifermentans sp. nov., which, according to Table 3, can be separated from other taxa of Gallibacterium.

For Gallibacterium group III, DNA-DNA hybridization results exist for strains F151 and F448, which showed $81 \%$ DNA reassociation (Piechulla et al., 1985), while only $25 \%$ DNA reassociation was observed between $\mathrm{F} 151$ and $\mathrm{F} 450^{\mathrm{T}}$ (16S rRNA gene sequence group I) and 20\% DNA reassociation between F448 and F420 (16S rRNA gene sequence group I). Finally, $25 \%$ DNA reassociation was observed between strain F283 (100\% DNA reassociation to $\mathrm{F} 150^{\mathrm{T}}$ of $16 \mathrm{~S}$ rRNA gene sequence group IV) and strain F418, which clustered with strain F448 of group III in AFLP (Bojesen et al., 2007) (Supplementary Table S3). Combination of previous AFLP results (Bojesen et al., 2007), the present sequence results (Fig. 1) and wholegenome similarities (Supplementary Table S2) clearly shows that 16S rRNA gene sequence group III should be classified as a novel species of Gallibacterium. However, Gallibacterium 16S rRNA gene sequence group III can not be separated clearly from the other taxa by biochemical traits, in particular Gallibacterium salpingitidis (Table 3). The group is unique according to protein profiling (phenon $2 \mathrm{~b}=$ pigeon isolates; phenon $2 \mathrm{c}=$ various avian species; phenon $4=$ parakeet), as stated previously by Bisgaard et al. (1993). The colony morphology for this group named as Gallibacterium genomospecies 3 is similar to that of other species of Gallibacterium and the Pasteurellaceae in general. Haemolysis and adherence to the agar are not observed. The reference strain F151 $(=$ CCUG $15565=$ NCTC 11412) was isolated from salpingitis in a duck and is catalase-positive and oxidasenegative. Weak acid production is observed from mucate. Urease is produced and weak growth is observed on MacConkey agar. Strains are indole-negative. Acid is 
produced from glycerol, (+ )-D-arabitol, (-)-D-arabinose, dulcitol and (-)-L-fucose. $\beta$-Xylosidase (ONPX) is not produced. Differences that separate Gallibacterium genomospecies 3 from the novel species G. melopsittaci and G. trehalosifermentans (Table 3 ) are stated in the descriptions of these species. Due to major phenotypic variation observed for Gallibacterium genomospecies 3, only the difference in acid formation from xylitol separates this species from G. salpingitidis, while differences in acid production from $(+)$-D-xylose and $(+)$-melibiose and $\alpha$ galactosidase activity separate Gallibacterium genomospecies 3 from Gallibacterium group V. Characters given in the description of $G$. melopsittaci in addition to $\alpha$-glucosidase (PNPG) separate Gallibacterium genomospecies 3 from G. anatis. Strains of Gallibacterium genomospecies 3 have been obtained from different lesions in pigeons, ducks, turkeys and psittacine birds.

Two of the four strains classified with 16S rRNA gene sequence group IV have been characterized previously by DNA-DNA hybridization (Piechulla et al., 1985). Strain F283, which clustered with $\mathrm{F} 150^{\mathrm{T}}$ by AFLP typing (Bojesen et al., 2007), also showed $100 \%$ DNA reassociation with this strain, while 74 and $51 \%$ DNA reassociation was observed with strains F416 and F420, respectively, and $45 \%$ DNA reassociation with F417, all of which represent $16 \mathrm{~S}$ rRNA gene sequence group I. Surprisingly, $95 \%$ DNA reassociation measured with a standard deviation of $1.0 \%$ was observed between F416 and 19987/2 (Supplementary Table S3), which clearly represent distinct genetic groups (Fig. 1 and Supplementary Table S2) and protein profiles (Bisgaard et al., 1993), although they represent the same biovar (Table 1). For the same reason, the DNA-DNA reassociation value stated probably represents an error. Combined with the present findings, which clearly show that $16 \mathrm{~S}$ rRNA gene sequence group IV represents a distinct group both genetically (Fig. 1 and Supplementary Table S2) and phenotypically, it is suggested that this group of bacteria is classified as a novel species of Gallibacterium, Gallibacterium salpingitidis sp. nov. Phenotypic characters that separate this species from other species are given in Table 3. Several phenotypic characters separate Gallibacterium 16S rRNA gene sequence group IV from G. anatis (Christensen et al., 2003a). In addition, protein profiling might be used for separation of the suggested species (Bisgaard et al., 1993).

Finally, group V represented by strain 39199/1L showed a maximum of $96.6 \% 16 \mathrm{~S}$ rRNA gene sequence similarity with related taxa and probably represents a novel species. In addition, whole-genome similarity values calculated from $r e c N$ sequences clearly demonstrate that this taxon, which has so far only been obtained from partridges and pheasants (Bisgaard, 1993), should be classified as a separate species of Gallibacterium. Two strains also represent a distinct phenon (3a) by protein profiling (Bisgaard et al., 1993) and AFLP (Bojesen et al., 2007), just as phenotypic characters separate these organisms from $G$. anatis (Christensen et al., 2003a) as well as other species of
Gallibacterium (Table 3). Since only two strains have been investigated, the species is not yet named and will be referred to as Gallibacterium group V.

\section{Emended description of the genus Gallibacterium Christensen et al. 2003}

All strains investigated are Gram-negative, non-motile at 22 and $37{ }^{\circ} \mathrm{C}$ and fermentative in Hugh \& Leifson's medium with glucose. Negative reactions are obtained in Simmons' citrate, malonate base, $\mathrm{KCN}$ growth and the Voges-Proskauer test at $37^{\circ} \mathrm{C}$ and $\mathrm{H}_{2} \mathrm{~S}$ is not produced in TSI. Gas is not produced from nitrate and none of the strains produce arginine dihydrolase, lysine decarboxylase, ornithine decarboxylase, phenylalanine deaminase, gelatinase or pigment. Symbiotic growth is not observed and haemolysis of bovine blood is observed only for Gallibacterium anatis biovar haemolytica. Isolates do not hydrolyse Tween 20 or 80 . All isolates are positive for the porphyrin, methyl red and phosphatase tests, reduce nitrate and produce alanine aminopeptidase. Acid is produced from (-)-D-mannitol, (-)-D-fructose, $(+)$-Dgalactose, (+)-D-glucose, mannose and sucrose. None of the members of the genus produce acid from mesoerythritol, adonitol, (-)-L-xylose, (+)-D-fucose, (+)-Lrhamnose, (-)-L-sorbose, cellobiose, (+)-melezitose, $(+)$-glycogen, inulin, aesculin, amygdalin, arbutin, gentiobiose, salicin, (+)-turanose or $\beta-N-\mathrm{CH}_{3}$-glucosamid. Negative reactions are observed for $\beta$-glucosidase (NPG), $\alpha$-fucosidase (ONPF), $\beta$-glucuronidase (PGUA) and $\alpha$ mannosidase. None of the strains produce gas from $(+)-$ D-glucose. Compared with the original description of Gallibacterium (Christensen et al., 2003a), activities of catalase and oxidase and acid production from glycerol and D-ribose should be regarded as variable following the inclusion of the species described below. The type species is Gallibacterium anatis (Christensen et al., 2003a).

\section{Description of Gallibacterium melopsittaci sp. nov.}

Gallibacterium melopsittaci (me.lo.psit.ta'ci. N.L. masc. gen. n. melopsittaci of Melopsittacus, a zoological name for a genus of parakeet, from which the type strain was isolated).

Isolates on blood agar form regular, circular, slightly raised, non-haemolytic colonies with an entire margin. Colonies are smooth, shiny and non-transparent with a greyish colour. After $24 \mathrm{~h}$ aerobic incubation at $37{ }^{\circ} \mathrm{C}$, colonies are $1.0-2.0 \mathrm{~mm}$ in diameter. Adherence to the agar is not observed and the consistency of the colonies is unguentlike. All isolates meet the phenotypic characters of the genus as stated above. The type strain is catalase- and oxidase-negative, and acid is not produced from mucate. Weak growth is observed on MacConkey agar. Acid is produced from $(+)$-D-xylose and $(-)$-D-sorbitol, but not from $(+)$-L-arabinose, $(-)$-D-arabinose, dulcitol or $(-)$-L- 
fucose. Differences in acid production from lactose and trehalose and $\beta$-galactosidase (ONPG) and $\alpha$-glucosidase (PNPG) activities separate Gallibacterium melopsittaci from Gallibacterium trehalosifermentans, while differences in acid production from $(+)$-melibiose and $\alpha$-galactosidase, $(+)$ $\mathrm{D}$-arabitol and xylitol, and urease and $(+)$-D-arabitol and $\beta$-xylosidase (ONPX) separate Gallibacterium melopsittaci from Gallibacterium genomospecies 3, Gallibacterium salpingitidis and Gallibacterium group V, respectively. Isolates have been obtained from septicaemia of parakeets and budgerigars and salpingitis in a parakeet.

The type strain, $\mathrm{F} 450^{\mathrm{T}}\left(=\right.$ CCUG $\left.36331^{\mathrm{T}}=\mathrm{CCM} 7538^{\mathrm{T}}\right)$, was isolated from septicaemia in a parakeet.

\section{Description of Gallibacterium trehalosifermentans sp. nov.}

Gallibacterium trehalosifermentans (tre.ha.lo'si.fer.men'tans. N.L. n. trehalosum trehalose; L. v. fermento to ferment; N.L. part. adj. trehalosifermentans trehalose-fermenting).

Colony morphology is similar to that of other species of Gallibacterium and members of the Pasteurellaceae in general. Haemolysis and adherence to the agar are not observed. The type strain is catalase- and oxidase-positive. Acid is produced from glycerol, (-)-D-arabinose and dulcitol. $\beta$-Xylosidase is not produced. Differences in at least four characters separate the species from the other novel species reported in this study (Table 3). Differences in $\beta$-galactosidase (ONPG) and $\alpha$-galactosidase activity separate the species from Gallibacterium anatis. Strains have been isolated from septicaemia in budgerigars.

The type strain, 52/S3/90 ${ }^{\mathrm{T}} \quad\left(=\mathrm{CCUG} 55631^{\mathrm{T}}=\mathrm{CCM}\right.$ $\left.7539^{\mathrm{T}}\right)$, was isolated from septicaemia in a budgerigar.

\section{Description of Gallibacterium salpingitidis sp. nov.}

Gallibacterium salpingitidis (sal.pin.gi'ti.dis. N.L. fem. gen. n. salpingitidis from an inflammation of the ovarial tube).

Colony morphology is similar to that observed for other species of Gallibacterium and members of the Pasteurellaceae in general. Haemolysis and adherence to the agar are not observed. The type strain is urease-positive and negative for acid production from (-)-D-sorbitol. Five phenotypic characters separate the species from Gallibacterium group V (Table 3). Differences that separate the species from the other species reported in this study are stated in the descriptions of those species. Finally, differences in acid production from $(+)$-L-arabinose, trehalose and dulcitol in addition to $\alpha$-glucosidase activity and haemolysis separate the species from Gallibacterium anatis (Christensen et al., 2003a). Strains have been obtained from reproductive tract lesions in web-footed birds and pericarditis in a cat. To avoid confusion with regard to the name, the names 'Pasteurella salpingitis' and 'Actinobacillus salpingitidis', not included on the Approved
Lists of Bacterial Names (Skerman et al., 1980), refer to Gallibacterium genomospecies 1 and 2 described by Christensen et al. (2003a), whereas Gallibacterium salpingitidis refers to taxon 2 of Bisgaard (1982).

The type strain, $\mathrm{F} 150^{\mathrm{T}}$ (=CCUG $15564^{\mathrm{T}}=$ CCUG $36325^{\mathrm{T}}$ $=$ NCTC $11414^{\mathrm{T}}$ ), was isolated from salpingitis in a duck.

\section{Acknowledgements}

We would like to thank Professor Dr Hans G. Trüper, Rheinische Friedrich-Wilhelms-Universität, Bonn, and Dr Jean Euzéby, Laboratoire de Bactériologie, École Nationale Vétérinaire, Toulouse, for help with the Latin names.

\section{References}

Altschul, S. F., Madden, T. L., Schaffer, A. A., Zhang, J., Zhang, Z., Miller, W. \& Lipman, D. J. (1997). Gapped BLAST and PSI-BLAST: a new generation of protein database search programs. Nucleic Acids Res 25, 3389-3402.

Angen, Ø., Ahrens, P., Kuhnert, P., Christensen, H. \& Mutters, R. (2003). Proposal of Histophilus somni gen. nov., sp. nov. for the three species incertae sedis 'Haemophilus somnus', 'Haemophilus agni' and 'Histophilus ovis'. Int J Syst Evol Microbiol 53, 1449-1456.

Beichel, E. (1986). Differenzierung von 130 X-und V-Faktorunabhängigen aviären Bakterienstämmen der Familie Pasteurellaceae Pohl 1981 unter besonderer Berücksichtigung neuer taxonomischer Erkenntnisse. Inaugural dissertation, Tierärztliche Hochschule Hannover, Germany (in German).

Bisgaard, M. (1975). Characterization of atypical Actinobacillus lignieresii isolated from ducks with salpingitis and peritonitis. Nord Vet Med 27, 378-383.

Bisgaard, M. (1982). Isolation and characterization of some previously unreported taxa from poultry with phenotypic characters related to Actinobacillus and Pasteurella species. Acta Pathol Microbiol Immunol Scand $[B]$ 90, 59-67.

Bisgaard, M. (1993). Ecology and significance of Pasteurellaceae in animals. Zentralbl Bakteriol 279, 7-26.

Bisgaard, M. (1995). Salpingitis in web-footed birds: prevalence, aetiology and significance. Avian Pathol 24, 443-452.

Bisgaard, M., Brown, D. J., Costas, M. \& Ganner, M. (1993). Whole cell protein profiling of Actinobacillus-like strains classified as taxon 2 and taxon 3 according to Bisgaard. Zentralbl Bakteriol 279, 92-103.

Bisgaard, M., Hinz, K.-H., Petersen, K. D. \& Christensen, J. P. (1999). Identification of members of the Pasteurellaceae isolated from birds and characterization of two new taxa isolated from psittacine birds. Avian Pathol 28, 369-377.

Bisgaard, M., Christensen, J. P., Bojesen, A. M. \& Christensen, H. (2007). Avibacterium endocarditidis sp. nov., isolated from valvular endocarditis in chickens. Int J Syst Evol Microbiol 57, 1729-1734.

Blackall, P. J., Christensen, H., Beckenham, T., Blackall, L. L. \& Bisgaard, M. (2005). Reclassification of Pasteurella gallinarum, [Haemophilus] paragallinarum, Pasteurella avium and Pasteurella volantium as Avibacterium gallinarum gen. nov., comb. nov., Avibacterium paragallinarum comb. nov., Avibacterium avium comb. nov. and Avibacterium volantium comb. nov. Int J Syst Evol Microbiol 55, 353-362.

Bojesen, A. M., Christensen, H., Nielsen, S. S. \& Bisgaard, M. (2007). Host-specific bacterial lineages in the taxon 2 and 3 complex of Pasteurellaceae. Syst Appl Microbiol 30, 119-127. 
Busse, H.-J., Bunka, S., Hensel, A. \& Lubitz, W. (1997). Discrimination of members of the family Pasteurellaceae based on polyamine patterns. Int J Syst Bacteriol 47, 698-708.

Christensen, H., Bisgaard, M. \& Olsen, J. E. (2002). Reclassification of equine isolates previously reported as Actinobacillus equuli, variants of A. equuli, Actinobacillus suis or Bisgaard taxon 11 and proposal of A. equuli subsp. equuli subsp. nov. and A. equuli subsp. haemolyticus subsp. nov. Int J Syst Evol Microbiol 52, 1569-1576.

Christensen, H., Bisgaard, M., Bojesen, A. M., Mutters, R. \& Olsen, J. E. (2003a). Genetic relationships among avian isolates classified as Pasteurella haemolytica, 'Actinobacillus salpingitidis' or Pasteurella anatis with proposal of Gallibacterium anatis gen. nov., comb. nov. and description of additional genomospecies within Gallibacterium gen. nov. Int J Syst Evol Microbiol 53, 275-287.

Christensen, H., Foster, G., Christensen, J. P., Pennycott, T., Olsen, J. E. \& Bisgaard, M. (2003b). Phylogenetic analysis by $16 \mathrm{~S}$ rDNA sequence comparison of avian taxa of Bisgaard and characterization and description of two new taxa of Pasteurellaceae. J Appl Microbiol 95, 354-363.

Christensen, H., Kuhnert, P., Busse, H.-J., Frederiksen, W. C. \& Bisgaard, M. (2007). Proposed minimal standards for the description of genera, species and subspecies of Pasteurellaceae. Int J Syst Evol Microbiol 57, 166-178.

De Ley, J., Mannheim, W., Mutters, R., Piechulla, K., Tytgat, R., Segers, P., Bisgaard, M., Frederiksen, W., Hinz, K.-H. \& Vanhoucke, M. (1990). Inter- and intrafamilial similarities of rRNA cistrons of the Pasteurellaceae. Int J Syst Bacteriol 40, 126-137.

Dewhirst, F. E., Paster, B. J., Olsen, I. \& Fraser, G. J. (1993). Phylogeny of the Pasteurellaceae as determined by comparison of $16 \mathrm{~S}$ ribosomal ribonucleic acid sequences. Zentralbl Bakteriol 279, 35-44.

Felsenstein, J. (1995). PHYLIP (phylogeny inference package) version 3.5c. Distributed by the author. Department of Genome Sciences, University of Washington, Seattle, USA.
Korczak, B., Christensen, H., Emler, S., Frey, J. \& Kuhnert, P. (2004). Phylogeny of the family Pasteurellaceae based on $r p o B$ sequences. Int $J$ Syst Evol Microbiol 54, 1393-1399.

Kuhnert, P. \& Korczak, B. M. (2006). Prediction of whole-genome DNA-DNA similarity, determination of $\mathrm{G}+\mathrm{C}$ content and phylogenetic analysis within the family Pasteurellaceae by multilocus sequence analysis (MLSA). Microbiology 152, 2537-2548.

Kuhnert, P., Frey, J., Lang, N. P. \& Mayfield, L. (2002). A phylogenetic analysis of Prevotella nigrescens, Prevotella intermedia and Porphyromonas gingivalis field strains reveals a clear species clustering. Int J Syst Evol Microbiol 52, 1391-1395.

Kuhnert, P., Korczak, B., Falsen, E., Straub, R., Hoops, A., Boerlin, P., Frey, J. \& Mutters, R. (2004). Nicoletella semolina gen. nov., sp. nov., a new member of Pasteurellaceae isolated from horses with airway disease. J Clin Microbiol 42, 5542-5548.

Kuhnert, P., Korczak, B. M., Christensen, H. \& Bisgaard, M. (2007). Emended description of Actinobacillus capsulatus Arseculeratne 1962, $38^{\mathrm{AL}}$. Int J Syst Evol Microbiol 57, 625-632.

Olsen, G. J., Matsuda, H., Hagstrom, R. \& Overbeek, R. (1994). fastDNAml: a tool for construction of phylogenetic trees of DNA sequences using maximum likelihood. Comput Appl Biosci 10, 41-48.

Piechulla, K., Bisgaard, M., Gerlach, H. \& Mannheim, W. (1985). Taxonomy of some recently described avian Pasteurellal Actinobacillus-like organisms as indicated by deoxyribonucleic acid relatedness. Avian Pathol 14, 281-311.

Skerman, V. B. D., McGowan, V. \& Sneath, P. H. A. (editors) (1980). Approved lists of bacterial names. Int J Syst Bacteriol 30, 225-420.

Thompson, J. D., Gibson, T. J., Plewniak, F., Jeanmougin, F. \& Higgins, D. G. (1997). The CLUSTAL_X windows interface: flexible strategies for multiple sequence alignment aided by quality analysis tools. Nucleic Acids Res 25, 4876-4882.

Zeigler, D. R. (2003). Gene sequences useful for predicting relatedness of whole genomes in bacteria. Int J Syst Evol Microbiol 53, 1893-1900. 